http://journal.unhas.ac.id

\title{
Analisis Vegetasi Tanaman Bawah Berkhasiat Obat Pada Sistem Agrisilvikultur di Lembang Sereale Toraja Utara
}

\author{
Resti Ura', Samuel A. Paembonan, Daud Malamassam \\ Fakultas Kehutanan Universitas Hasanuddin Makassar \\ E-mail:uraresti@yahoo.com
}

\begin{abstract}
Abstrak
Analisis vegetasi dilakukan untuk mengetahui seberapa besar sebaran berbagai spesies dalam suatu area melalui pengamatan langsung. Oleh karena itu maka dilakukan penelitian mengenai analisis vegetasi tumbuhan bawah berkhasiat obat pada sistem agrisilvikultur di Lembang Sereale Toraja Utara. Metode penelitian yang digunakan adalah metode analisis deskriptif kualitatatif. Hasil penelitian jenis tumbuhan bawah berkhasiat obat pada sistem agrisilvikultur dapat disimpulkan bahwa terdapat 9 jenis dari 7 familia tanaman bawah berkhasiat obat yang dibudidayakan oleh masyarakat dalam sistem agrisilvikultur. Indeks Nilai Penting (INP) pada tanaman bawah berkhasiat obat tertinggi adalah jenis Colocasia esculenta sebanyak 103,05\% merupakan tanaman yang dominan dan terendah pada jenis tanaman Sauropus androgymus dan Orthosiphon aristatus sebanyak 3,82\% merupakan jenis yang tidak dominan. Sistem agrisilvikultur di Lembang Sereale memiliki indeks kekayaan jenis termasuk dalam kategori rendah $(R=1,508)$, nilai indeks keanekaragaman jenis berada pada kategori rendah $\left(H^{\prime}=0,843\right)$, dan nilai indeks kemerataan jenis kategori rendah $(E=0,383)$.
\end{abstract}

Kata kunci: vegetasi, tumbuhan bawah, agrisilvikultur

\section{PENDAHULUAN}

Agrisilvikultur merupakan sistem penggunaan lahan yang memadukan penanaman pohonpohon dengan tanaman semusim berupa tanaman bahan makanan atau tanaman-tanaman lainnya sebagai komoditas (Nurkin, 2012). Kebiasaan atau budaya, luas pemilikan lahan, ketersediaan modal dan harga komoditas (hasil pertanian) dipasaran memengaruhi pola penyusunan ruang, struktur dan komposisi jenis tanaman sistem agroforestri yang dikembangkan oleh masyarakat suatu daerah. Apabila masyarakat memiliki budaya dan kebiasaan memanfaatkan jenis-jenis tanaman tertentu dalam kehidupan sehari-hari atau upacara adat maka dalam praktek agroforestrinya akan ditemukan jenisjenis tanaman tersebut. Semakin banyak variasi jenis yang digunakan, maka semakin bervariasi struktur dan komposisi jenis tanaman agroforestri yang dikembangkannya (Millang, 2010).

Tumbuhan bawah adalah komunitas tanaman yang menyusun stratifikasi bawah dekat permukaan tanah. Tumbuhan ini umumnya berupa rumput, herba, semak atau perdu rendah. Jenisjenis vegetasi ini ada yang bersifat annual, biannual, atau perenial dengan bentuk hidup soliter, berumpun, tegak menjalar atau memanjat (Suharti, 2015). Pemanfaatan tumbuhan bawah berkhasiat obat atau herbal menjadi salah satu alternatif bagi masyarakat untuk menjaga kesehatan dan mengobati suatu penyakit, hal ini disebabkan karena penggunaan tumbuhan berkhasiat obat atau herbal di 


\section{Resti Ura' dkk/Jurnal Ilmu Alam dan Lingkungan 8 (16) (2017) 45 - 51}

samping harganya yang cukup terjangkau juga tidak menimbulkan efek samping dibandingkan dengan obat-obatan dari bahan kimia (Wibisono dan Azham, 2017).

Vegetasi merupakan kumpulan beberapa jenis tumbuh-tumbuhan yang tumbuh bersama-sama pada satu tempat dimana terdapat interaksi yang erat antara individu penyusunya, baik antara tumbuhtumbuhan maupun dengan hewan-hewan yang hidup dalam vegetasi dan lingkungan. Analisis vegetasi merupakan cara yang dilakukan untuk mengetahui seberapa besar sebaran berbagai spesies dalam suatu area melalui pengamatan langsung, oleh karena itu maka dilakukan penelitian mengenai analisis vegetasi tumbuhan bawah berkhasiat obat pada sistem agrisilvikultur di Lembang Sereale Toraja Utara.

\section{METODE PENELITIAN}

Penelitian dilakukan pada sistem agrisilvikultur di Lembang Sereale Toraja Utara. Teknik pengumpulan data vegetasi pada penelitian ini menggunakan analisis deskriptif kualitatatif dengan menghitung jumlah jenis tumbuhan bawah, indeks kekayaan jenis, indeks keanekaragaman, dan indeks kemerataan jenis, melalui data yang diperoleh dari pengamatan langsung di lapangan. Populasi dalam penelitian ini adalah semua spesies tanaman bawah berkhasiat obat yang hidup pada sistem agrisilvikultur di Lembang Sereale Toraja Utara. Pengambilan data vegetasi dilakukan dengan membuat plot pengamatan secara purposif sampling dengan ukuran plot penelitian adalah $25 \times 25 \mathrm{~m}$ sebanyak 3 (tiga) kali pengulangan.

\section{Analisis Data}

Analisis vegetasi merupakan cara untuk mempelajari komposisi jenis dan struktur vegetasi dalam suatu ekosistem, dalam melakukan analisis vegetasi variabel yang diamati antara lain: Indeks Nilai Penting merupakan indeks kepentingan yang menggambarkan pentingnya peranan suatu jenis vegetasi dalam ekosistemnya. Indeks Nilai Penting (INP) pada tumbuhan bawah $=F R+K R$ (Lahusen, dkk., 2014; Ismaini, dkk., 2015; Bachtiar dan Ura', 2016). Indeks Nilai Penting diperoleh dengan menggunakan rumus sebagai berikut:

$$
\begin{aligned}
& \text { Kerapatan }(\mathrm{K}) \quad=\frac{\text { fumlah individu }}{\text { Luas contoh }} \\
& \text { Kerapatan Relatif }(\mathrm{KR})=\frac{\text { Kerapatan suatu jenis }}{\text { Kerapatan total seluruh jenis }} \times 100 \% \\
& \text { Frekuensi }(\mathrm{F}) \quad=\frac{\text { Iumlah plot ditemukannya suatu jenis }}{\text { Jumlah sefuruh plot }} \\
& \text { Frekuensi relatif }(\mathrm{FR}) \quad=\frac{\text { Frekuensi suatu jenis }}{\text { Frekuensi seluruh jenis }} \times 100 \%
\end{aligned}
$$

Indeks kekayaan Jenis digunakan untuk mencari kekayaan spesies jenis pohon dan burung maka dapat dihitung menggunakan Indeks Margalef,yaitu:

$$
R=\frac{S-1}{\operatorname{Ln} \cdot N}
$$

Dimana : R (indeks kekayaan jenis Margalef), $\mathrm{S}$ (jumlah jenis yang teramati), $\mathrm{N}$ (jumlah individu (seluruh jenis) yang teramati), dan Ln (logaritma natural) 
Tabel 1. Kriteria Indeks Kekayaan Jenis Margalef

\begin{tabular}{cccc}
\hline Kriteria & Tinggi & Sedang & Rendah \\
\hline Indeks Kekayaan Jenis Margalef (R) & $>5,0$ & $3,5-5,0$ & $<3,5$ \\
\hline
\end{tabular}

Indeks keanekaragaman jenis digunakan untuk mengetahui pengaruh gangguan terhadap lingkungan atau untuk mengetahui tahapan suksesi dan kestabilan dari komunitas tumbuhan pada suatu lokasi (Lahusen, dkk., 2014, Bachtiar dan Ura', 2016). Tingkat Keanekaragaman Jenis bagi komponen penyusun menggunakan Shannon Index (Ludwig and Reynolds,1988):

$$
\mathbf{H}^{\prime}=-\sum\{(\mathbf{n i} / \mathbf{n}) \ln \{(\mathbf{n i} / \mathbf{n})\}
$$

Dimana : H'(Keanekaragaman jenis), ni (Jumlah individu setiap jenis) dan n (Total individu)

Kriteria komunitas berdasarkan indeks keanekaragaman hayati ditunjukkan pada tabel berikut:

Tabel 2. Kriteria Komunitas Berdasarkan Indeks Keanekaragaman Hayati

\begin{tabular}{cccc}
\hline Kriteria & Rendah & Sedang & Tinggi \\
\hline Indeks Keanekaragaman & $\mathrm{H}^{\prime}<1$ & $1<\mathrm{H}^{\prime}<3$ & $\mathrm{H}^{\prime}>3$ \\
\hline
\end{tabular}

Indeks kemerataan Jenis digunakan untuk mencari kemerataan jenis pohon dapat dihitung menggunakan Rasio Hill yang dimodifikasi (Fachrul, 2012; Ismaini, dkk., 2015) sebagai berikut:

$$
\mathbf{E}=\mathbf{H}^{\prime} / \mathbf{H m a x}=\mathbf{H}^{\prime} / \mathbf{L n S}
$$

Dimana : S (Jumlah Total Jenis), H' (Nilai Indeks Shanon Wiener), E= 0 (Kemerataan antara jenis rendah), dan $\mathrm{E}=1$ (Kemerataan antar jenis relatif merata atau jumlah individu masingmasing jenis relatif sama)

\section{HASIL DAN PEMBAHASAN}

Hasil penelitian pada Tabel 3. didapatkan jenis tanaman bawah berkhasiat obat pada sistem agrisilvikultur di Lembang Sereale menunjukkkan terdapat 9 jenis dari 7 familia tanaman berkhasiat obat yang dibudidayakan oleh masyarakat dalam sistem agrisilvikultur. Sistem agrisilvikultur merupakan subsistem yang memungkinkan terbentuknya hutan serbaguna dalam memenuhi berbagai kebutuhan masyarakat akan kayu pertukangan, kayu bakar, madu, bahan obat-obatan, dan makan ternak.

Tabel 3. Jenis-Jenis Tanaman Bawah Berkhasiat Obat pada Sistem Agrisilvikultur di Lembang

\begin{tabular}{|c|c|c|c|}
\hline $\begin{array}{c}\text { Jenis } \\
\text { Tanamar }\end{array}$ & Nama Ilmiah & Familia & Khasiat Obat \\
\hline Talas & $\begin{array}{l}\text { Colocasia esculenta (L.) } \\
\text { Schott. }\end{array}$ & Araceae & $\begin{array}{l}\text { Luka, mencegah diabetes dan } \\
\text { melawan kanker }\end{array}$ \\
\hline Ubi jalar & Ipomoea batatas $\mathrm{L}$. & Convolvulaceae & $\begin{array}{l}\text { Asam urat, penambah darah } \\
\text { dan diabetes }\end{array}$ \\
\hline Ubi Kayu & Manihot esculenta Crantz & Euphorbiaceae & Luka bakar dan diare \\
\hline Katuk & $\begin{array}{l}\text { Sauropus androgynus (L.) } \\
\text { Merr. }\end{array}$ & Euphorbiaceae & $\begin{array}{l}\text { melancarkan ASI dan } \\
\text { Mencegah osteoporosis }\end{array}$ \\
\hline
\end{tabular}
Sereale 


\begin{tabular}{|c|c|c|c|}
\hline Serei & $\begin{array}{l}\text { Cymbopogon citratus (DC.) } \\
\text { Stapf }\end{array}$ & Gramineae & $\begin{array}{l}\text { sakit gigi, sakit perut, batuk, } \\
\text { dan rematik }\end{array}$ \\
\hline $\begin{array}{l}\text { Kumis } \\
\text { Kucing }\end{array}$ & $\begin{array}{l}\text { Orthosiphon aristatus (BL.) } \\
\text { Miq. }\end{array}$ & Lamiaceae & $\begin{array}{l}\text { Diare, diabetes, hipertensi dan } \\
\text { ginjal }\end{array}$ \\
\hline Miyana & $\begin{array}{l}\text { Coleus scutellarioides (L.) } \\
\text { Bth. }\end{array}$ & Lamiaceae & $\begin{array}{l}\text { Paru-paru basa, malaria dan } \\
\text { gangguan pernapasan }\end{array}$ \\
\hline Hanjuang & Cordyline fruticosa A. Chev. & Liliaceae & $\begin{array}{l}\text { kencing berdarah, kanker dan } \\
\text { TBC }\end{array}$ \\
\hline Lengkuas & Languas galanga (L.) stuntz. & Zingeberaceae & $\begin{array}{l}\text { kurap, anti kanker dan } \\
\text { rematik }\end{array}$ \\
\hline
\end{tabular}

Tabel 4. Kerapatan, Kerapatan Relatif, Frekuensi, dan Frekuensi Relatif Tumbuhan Bawah Berkhasiat Obat

\begin{tabular}{lrrrrr}
\hline \multicolumn{1}{c}{ JENIS } & JUMLAH & K & KR & F & \multicolumn{1}{c}{ FR } \\
\hline Colocasia esculenta (L.) Schott. & 174 & 0.0928 & 79.45 & 1.00 & 23.60 \\
Ipomoea batatas L. & 5 & 0.0027 & 2.28 & 0.33 & 7.87 \\
Manihot esculenta Crantz & 17 & 0.0091 & 7.76 & 1.00 & 23.60 \\
Sauropus androgynus (L.) Merr. & 1 & 0.0005 & 0.46 & 0.14 & 3.37 \\
Cymbopogon citratus (DC.) Stapf & 4 & 0.0021 & 1.83 & 0.14 & 3.37 \\
Orthosiphon aristatus (BL.) Miq. & 1 & 0.0005 & 0.456 & 0.14 & 3.37 \\
Coleus scutellarioides (L.) Bth. & 10 & 0.0053 & 4.57 & 0.67 & 15.73 \\
Cordyline fruticosa A. Chev. & 5 & 0.0027 & 2.28 & 0.67 & 15.73 \\
Languas galanga (L.) stuntz. & 2 & 0.0011 & 0.91 & 0.14 & 3.37 \\
Grand Total & $\mathbf{2 0 1}$ & $\mathbf{0 . 1 1 6 8}$ & $\mathbf{1 0 0 . 0 0}$ & $\mathbf{4 . 2 4}$ & $\mathbf{5 8 . 4 3}$ \\
\hline
\end{tabular}

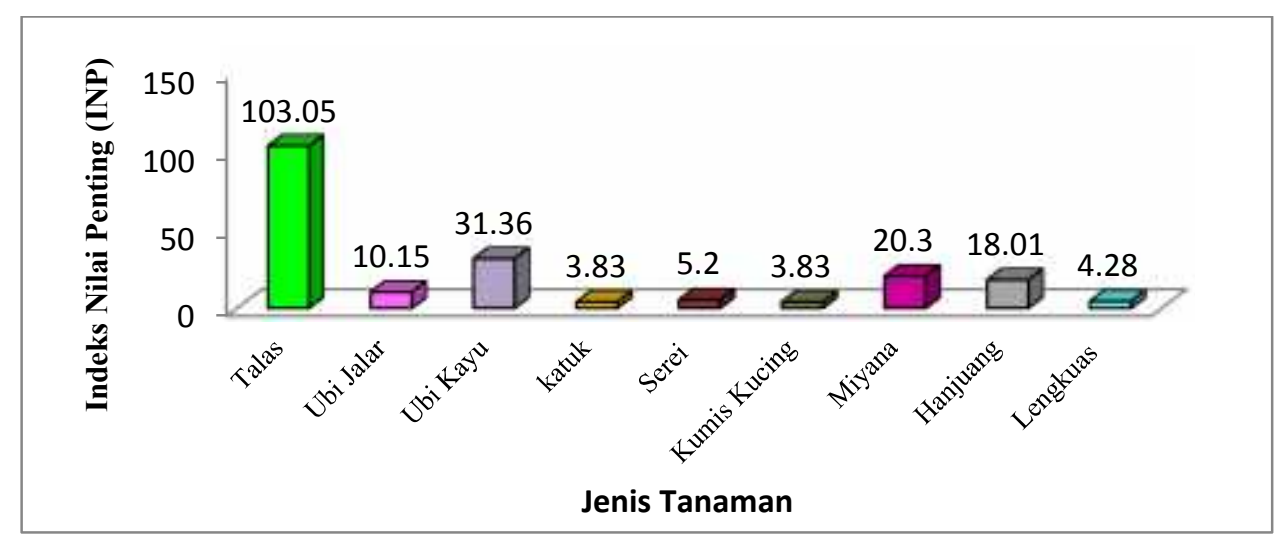

Gambar 1. Histogram perbandingan nilai indeks nilai penting (INP).

Hasil penelitian pada Gambar 1. menunjukkan indeks nilai penting (INP) tertinggi pada tanaman bawah berkhasiat obat di Lembang Sereale adalah jenis Colocasia esculenta sebanyak $103,05 \%$ dan terendah pada jenis tanaman Sauropus androgymus dan Orthosiphon aristatus sebanyak $3,82 \%$. Indriyanto (2006) mengatakan, bahwa tumbuhan dengan nilai INP yang tertinggi merupakan 


\section{Resti Ura' dkk/Jurnal Ilmu Alam dan Lingkungan 8 (16) (2017) 45 - 51}

jenis yang paling dominan di suatu komunitas. Tumbuhan yang memiliki dominansi paling rendah akan ditunjukkan dengan nilai INP terkecil (Azizah, 2017).

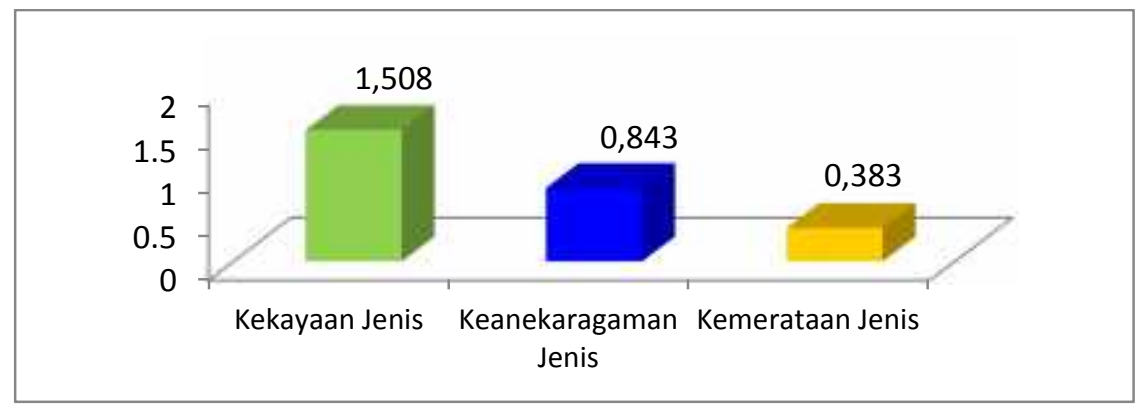

Gambar 2. Histogram Indeks Kekayaan Jenis, Indeks Keanekaragaman Jenis dan Kemerataan Jenis Vegetasi pada Sistem Agrisilvikultur di Lembang Sereale Toraja Utara.

Hasil analisis vegetasi tumbuhan berkhasiat obat di Lembang Sereale Toraja Utara pada Gambar 2. menunjukkan, bahwa nilai indeks kekayaan jenis Margalef yaitu 1,508 termasuk dalam kategori rendah. Semakin banyak jumlah jenis yang ditemukan maka indeks kekayaannya juga semakin besar. Indeks kekayaan Margalef membagi jumlah spesies dengan fungsi logarima natural yang mengindikasikan, bahwa pertambahan jumlah spesies berbanding terbalik dengan pertambahan jumlah individu. Hal ini juga menunjukkan bahwa biasanya pada suatu komunitas/ekosistem yang memiliki banyak spesies akan memiliki sedikit jumlah individunya pada setiap spesies (Ismaini, dkk., 2015).

Nilai indeks keanekaragaman jenis yaitu 0,843 kategori rendah. Semakin kecil jumlah spesies dan variasi jumlah individu tiap spesies maka keanekaragaman suatu ekosistem semakin kecil. Keadaan seperti ini dapat menyebabkan ketidakseimbangan ekosistem apabila terjadi gangguan atau tekanan dari lingkungan, yang berarti hanya jenis tertentu yang mampu bertahan hidup (Nugroho, dkk., 2015).

Nilai indeks kemerataan jenis yaitu 0,383 kategori rendah. Indeks kemerataan menunjukkan derajat kemerataan kelimpahan individu antara setiap spesies. Apabila setiap jenis memiliki jumlah individu yang sama, maka komunitas tersebut mempunyai nilai evenness maksimum. Sebaliknya, jika nilai kemerataan kecil, maka dalam komunitas tersebut terdapat jenis dominan, sub-dominan dan jenis yang terdominasi, maka komunitas itu memiliki evenness minimum. Nilai kemerataan memiliki rentang antara $0-1$, jika nilai indeks yang diperoleh mendekati satu berarti penyebarannya semakin merata (Ismaini, dkk., 2015).

Rendahnya nilai kekayaan jenis, keragaman jenis, dan kemerataan jenis juga disebabkan oleh adanya pengaruh naungan pohon yang ditanam oleh masyarakat setempat, sehingga memengaruhi pertumbuhan tanaman bawah dalam hal pemenuhan akan cahaya matahari yang membantu tanaman dalam proses fotosintesis. Ketersediaan nutrisi dan pemanfaatan nutrisi yang berbeda menyebabkan tingkat keanekaragaman dan tingkat kemerataan tumbuhan di suatu tempat menjadi bervariasi (Aththorick, dkk., 2006). Pengetahuan masyarakat setempat masih kurang dalam hal membudidayakan dan manfaatkan potensi tanaman bawah berkhasiat obat pada sistem agrisilvikultur menjadi faktor kendala yang memengaruhi perbanyakan dan komposisi jenis tanaman sehingga nilai kekayaan jenis, keragaman jenis, dan kemerataan jenis tergolong rendah. 


\section{Resti Ura' dkk/Jurnal Ilmu Alam dan Lingkungan 8 (16) (2017) 45 - 51}

Persaingan akan meningkatkan daya juang untuk mempertahankan hidup, jenis yang kuat akan menang dan menekan yang lain, sehingga jenis yang kalah menjadi kurang adaptif dan menyebabkan tingkat reproduksi rendah dan kepadatannya juga sedikit (Kunarso dan Azwar, 2013). Tumbuhan bawah sangat berpengaruh dari pencahayaan sinar matahari serta jenis spesies yang hidup sebagai tempat naungan. Tumbuhan bawah memiliki banyak manfaat bagi lingkungan diantaranya adalah dapat membantu menjaga agregat tanah agar tidak mudah lepas dan tererosi oleh air hujan maupun aliran permukaan (Hilwan, dkk., 2013).

\section{KESIMPULAN}

Hasil penelitian jenis tumbuhan bawah berkhasiat obat pada sistem agrisilvikultur dapat disimpulkan bahwa terdapat 9 jenis dari 7 familia tanaman bawah berkhasiat obat yang dibudidayakan oleh masyarakat dalam sistem agrisilvikultur. Indeks Nilai Penting (INP) pada tanaman bawah berkhasiat obat tertinggi adalah jenis Colocasia esculenta sebanyak 103,05\% merupakan tanaman yang dominan dan terendah pada jenis tanaman Sauropus androgymus dan Orthosiphon aristatus sebanyak 3,82\% merupakan jenis yang tidak dominan. Sistem agrisilvikultur di Lembang Sereale memiliki indeks kekayaan jenis termasuk dalam kategori rendah $(\mathrm{R}=1,508)$, nilai indeks keanekaragaman jenis berada pada kategori rendah $\left(\mathrm{H}^{\prime}=0,843\right)$, dan nilai indeks kemerataan jenis kategori rendah $(\mathrm{E}=0,383)$.

\section{DAFTAR PUSTAKA}

Azizah, P. N., 2017. Analisis Vegetasi di Kawasan Sekitar Mata Air Ngembel, Kecamatan Pajangan, Kabupaten Bantul. Jurnal Riset Daerah, Vol. XVI, No.1, Hal. 2685 - 2701, April 2017.

Aththorick, T.A., R. Widhiastuti, dan A. Evanius, 2006. Studi keanekaragaman Pohon pada Tiga Zona Ketinggian Hutan Pegunungan Gunung Sinabung Kabupaten Karo. Jurnal Komunikasi Penelitian, Vol. 18, No.3, Hal. 32-39.

Bachtiar, B. dan R. Ura', 2016. Keanekaragaman Jenis Pohon Ruang Terbuka Hijau di Kebun Raya Jompie Pare-Pare. Jurnal Ilmu Alam dan Lingkungan, Vol. 7 , No. 14, Hal. 1-7, Agustus 2016. ISSN: 2086-4604.

Fachrul, M. F., 2007. Metode Sampling Bioekologi. Bumi Aksara. Jakarta.

Hilwan A., D. Mulyana, dan W. G. Pananjung, 2013. Keanekaraaman Jenis Tumbuhan Bawah pada Tegakan Sengon Buto (Enterolobium cyclocarpum Griseb.) dan Trembesi (Samanea saman Merr.) di Lahan Pasca Tambang Batubara PT Kitadin, Embalut, Kutai Kartanagara, Kalimantan Timur.

Indriyanto, 2006. Ekologi Hutan. Jakarta: Bumi Aksara.

Ismaini, L., M. Lailati, Rustandi, dan D. Sunandar, 2015. Analisis Komposisi dan Keanekaragaman Tumbuhan di Gunung Dempo, Sumatera Selatan. Prosiding Seminar Nasional Masyarakat Biodiversitas Indonesia, Vol. 1, No. 6, Hal. 1397-1402, September 2015, ISSN: 2407-8050.

Kunarso, A., dan F. Azwar, 2013. Keragaman Jenis Tumbuhan Bawah pada Berbagai Tegakan Hutan Tanaman di Benakat, Sumatera Selatan. Jurnal Penelitian Hutan Tanaman Vol. 10 No. 2, Hal. 85- 98, Juni 2013ISSN: 1829-6327.

Lahusen, M. R, Naharuddin, dan Sustri, 2014. Keanekaragaman Jenis Vegetasi Tepian Sungai Kaili Desa Labuan Kungguma Kecamatan Labuan. Warta Rimba, Vol. 2, No. 1, Hal. 136-144, Juni 2014. ISSN: 2406-8373.

Ludwiq, JA. and J.F. Reynolds 1988. Statistical Ecology: Apimer on Methods and Computing. John Wiley and Sons. New York.

Millang, S., 2010. Struktur, Komposisi, dan Pemilihan Jenis Komponen Sistem Agroforestri di Desa Makuang, Kabupaten Mamasa. Jurnal SATRIA (Seri Ilmu Pengetahuan Alam) Edisi VI - Juli 2010.

Nugroho, A. S., T. Anis dan M. Ulfah, 2015. Analisis Keanekaragaman Jenis Tumbuhan Berbuah di Hutan Lindung Surokonto, Kendal, Jawa Tengah dan Potensinya Sebagai Kawasan Konservasi 
Burung. Prosiding Seminar Nasional Masyarakat Biodiversitas Indonesia,Vol. 1, No. 3, Hal. 472-476, Juni 2015 ISSN: 2407-8050.

Nurkin, B., 2012. Pengantar Silvikultur. Masagena Press. Makassar.

Wibisono, Y. dan Z. Azham, 2017. Inventarisasi Jenis Tumbuhan yang Berkhasiat Sebagai Obat pada Plot Konservasi Tumbuhan Obat di KHDTK Samboja Kecamatan Samboja Kabupaten Kutai Kartanegara. Jurnal AGRIFOR, Vol. XVI No. 1, hal. 125 - 140, Maret 2017 ISSN P: 14126885 ISSN O: 2503-4960.

Suharti, S., 2015. Pemanfaatan Tumbuhan Bawah di Zona Pemanfaatan Taman Nasional Gunung Merapi oleh Masyarakat Sekitar Hutan. Prosiding Seminar Nasional Masyarakat Biodiversitas Indonesia, Vol.1, No.6, Hal. 1411-1415, September 2015, ISSN: 2407-8050. 